\title{
Meslek Yüksekokulu Öğrencilerinin Azim İle Mutluluk Düzeylerinin İncelenmesi ${ }^{1}$
}

DOI: 10.26466/opus.569805

\author{
* \\ Nezir Ekinci* ${ }^{*}$ Erdal Hamarta** \\ * Öğr. Gör., Karamanoğlu Mehmetbey Üniversitesi,Kazım Karabekir MYO, / Karaman / Türkiye \\ E-Posta: ekincinezir@gmail.com \\ ORCID: 0000-0002-2065-2992 \\ ** Prof. Dr., Necmettin Erbakan Üni., Ahmet Keleşoğlu Eğitim Fakültesi, Meram / Konya/ Türkiye \\ E-Posta: erdalhamarta@gmail.com \\ ORCID: 0000-0003-0925-3824
}

\section{$\ddot{O} z$}

$B u$ araştırmanın amacı meslek yüksekokulu öğrencilerinin azim düzeyleri ile mutluluk düzeylerini belirlemeye yönelik olup azim düzeyleri ile mutluluk düzeyleri arasındaki ilişkiyi incelenmektir. Araştırmada nicel araştırma yöntemlerinden genel tarama modellerinden ilişkisel tarama tekniği kullanılmıştır. Çalışma grubunu Karamanoğlu Mehmetbey Üniversitesi Kazım Karabekir Meslek Yüksekokulu'da 2018- 2019 eğitim öğretim yılında öğrenim gören öğrenciler oluşturmaktadır. Farklı bölümlerde öğrenim görmekte 273' ü kadın, 81' i erkek olan toplam 354 öğrenci uygun örnekleme yöntemiyle seçilmiştir. Araştırma verileri Kısa Azim Ölçeği Formu, Oxford Mutluluk Ölçeği Kısa Formu ve araştırmacı tarafindan oluşturulan kişisel bilgi formu kullanılarak elde edilmiştir. Verilerin analizi, Spss programı ile Pearson momentler çarpım korelasyonu ve bağımsız gruplar için t testi teknikleri kullanılarak yapılmıştır. Araştırma sonucunda cinsiyet açısından, erkek öğrenciler ile kız öğrenciler arasında azim düzeyleri ve mutluluk düzeyleri arasında anlaml düzeyde bir fark bulunmamıştır. Bununla birlikte araştırmaya katılan meslek yüksekokulu öğrencilerinin azim düzeyleri ile mutluluk düzeyleri arasında düşük düzeyde anlaml bir ilişki olduğu bulunmuştur. Araştırma sonuçlarına göre önerilerde bulunulmuştur.

Anahtar Kelimeler: Meslek yüksekokulu öğrencileri, azim, mutluluk.

\footnotetext{
${ }^{1}$ Bu araştırma 3. Uluslararası Eğitim ve Sosyal Bilim Kongresi (INES-ESS 2018)'nde sözlü bildiri olarak sunulmuştur.
} 


\title{
Investigation of The Level of Grit and Happiness of Vocational High School Students
}

\begin{abstract}
The aim of this research is to determine the level of happiness of the students of vocational schools to investigate the relationship between grit levels and happiness levels. In this study, quantitative research methods from general screening models were used as a relational screening technique. The study group consists of students studying at Kazım Karabekir Vocational School of Karamanoğlu Mehmetbey University in the 2018 - 2019 academic year. A total of 354 students, 273 of whom were female and 81 of whom were male, were selected with appropriate sampling method. Research data were obtained by using the Short Grit Scale Form, the Oxford Happiness Scale Short Form and the personal information form created by the researcher. Data were analyzed by using Spss program and Pearson moment product correlation and test techniques for independent groups. As a result of the study, no significant difference was found between male students and female students in terms of grit levels and happiness levels. On the other hand, it was found that there was a low level of meaningful relationship between the levels of grit and happiness of the vocational school students participating in the research. Suggestions were made according to the results of the research.
\end{abstract}

Keywords: Vocational high school students, grit, happiness 


\section{Giriş}

İnsanlar yaşamları boyunca hem olumsuz düşüncelerden ve duygulardan uzak kalmaları hem de kendilerini geliştirmeleri için mutlu olmaları gerekir (Eryılmaz, 2016). Mutlu olan bireylerin kendini geliştirmesi ise kendinde varolan yeteneğin performansa dönüşmesi, hedefleri doğrultusunda emek vermesi ve çaba sarfetmesi sonucunda gerçekleşebilir. Bireyin yeteneklerini beceri haline dönüştürmesi için gerekli olan tekrarlı bir çabadır. Sürekli olarak gösterilen çaba beceriyi de başarıya dönüştürecektir. Uzun vadeli hedfeleri için insanlar karşılarına çıkan engelleri aşmaları ve hedeflerine ulaşmaları için azimli olmaları ve çaba göstermeleri gerekir (Duckworth, 2007).

Üniversite öğrencileri hayatlarındaki önemli dönemlerden biri olan meslek seçimi ve başarısı için kritik bir evrededirler. Bu evrenin başarılı olabilmesi için bilişsel olarak sınırları belirlenmiş bir amaç, davranışsal olarak tekrarlı bir uygulama ve duygusal olarak ise ilgi ve umut özelliklerinin öğrencilerde bulunması gereklidir (Duckworth, 2018).

Belirtilen kişilik özellikleri ya sahip olunan ya da sahip olunmayan türden nitelikler değildir. Öğrenciler kendi yetenek ve değerlerine uygun amaç edinebilirler, ilgi alanlarını farkedip geliştirebilir ve derinlerştirebililer. Disiplini alışkanlık haline getirebilir; hergün amaçları doğrultusunda düzenli ve sürekli bir şekilde çaba gösterebilirler (Duckworth, 2007). Tüm bunları yaparken öğrenciler yani; uzun vadeli hedefleri için çalışırken çeşitli engeller ile karşılaşabilirler. Bu durumlarda ise umut kişilik özellliğine sahip olanlar mücadelerine devam edeceklerdir. Dört kıymetli kişilik özelliği bireyin aynı zamanda azim seviyesini de oluşturmaktadır (Duckworth, 2007, 2018).

$\mathrm{Bu}$ araştırmanın temel amacı meslek yüksekokulu öğrencilerinin azim ile mutluluk düzeylerinin incelenmesi olup, alt amacı ise cinsiyet değişkenine göre azim ve mutluluk seviyelerinde farklılaşma olup olmadığını araştırmaktadır.

Hayatlarına azim ile devam eden öğrencilerin yaşamdan daha fazla doyum alabilecekleri varsayımı bu araştırmanın temelllerini oluşturmaktadır. Yaşamlarından daha fazla doyum alan öğrencilerin ise mutluluk seviyelerinin artması beklenmektedir (Eryılmaz, 2016). 
Azim kelime anlamı olarak bir işteki engelleri yenme kararlılığı olarak tanımlanmaktadır (TDK, 2011). Azim kavramı ile ilgili olarak daha farklı tanımlamalar hem yurt içi hem de yurtdışı alan yazında bulunmaktadır. Yurt içi çalışmalarda İngilizce 'grit' kelimesinin karşıllı̆ 1 olarak azim, kararlılık ve sebat anlamlarının kullanıldığ 1 görülmektedir. Yapılan bu araştırma kapsamında, psiko-eğitim uygulamalarında ve terim ifade edilirken 'grit' kelimesinin Türkçesi olarak azim ifadesinin kullanılması kararlılık ve sebat kelimelerine göre daha uygun ve anlamlı bulunmuştur.

Uluslararası alan yazında azim araştırmalarının öncüsü olan Duckworth tarafından azim başlığı yeni bir yapı olarak tanıtıldı. Uzun vadeli hedefler için sebat ve tutku olarak tanımlanan yapı, mevcut yapılardan farklı olarak sürekli çaba ve zaman içinde odaklanmış ilgi vurgusunu yapmaktadır (Duckworth, 2006). Dumfart ve Neubauer (2016) 'a göre, azim; başarı çabası, öz kontrol ve ilgi tutarlılığı yönlerini bütünleştirir ve bireylerde var olan yeteneklerin gerçekleşmesini teşvik eder.

Kelly ve arkadaşları (2014), ise azmi, belirli bir ilgi veya hedefin sürekli ve tutkulu bir şekilde bireyde var olması olarak kavramlaştırdılar. Azim için, çaba ve ilginin birkaç yıl boyunca sürdürüldüğü ve bir işte uzun vadeli dayanıklılığın olması gerektiğini özellikle belirttiler (2018, Collaço). Abuhassàn ve Bates (2015), azmi kendi kendini kontrol etmenin bir ölçüsü olarak tanımlamaktadır. Araştırmacılar, azmi bilişsel yeteneklerden büyük ölçüde farklı olarak tanımlamışlardır (Duckworth vd, 2007; Duckworth ve Quinn, 2009; Perkins-Gough, 2013). Azim aynı zamanda bir performans karakter gücü olarak da gösterildi. Bir bireyin belirli bir işte potansiyelini gerçekleştirme, çaba göstermede ve başarılı olmada kullandığı nitelikler olarak tanımlandı (Soutter ve Seider, 2013, s.352).

Bir diğer araştırmacı Bashant (2014), azimli bireylerin uzun vadeli hedeflerine yönelik bir amaç anlayışı ile çalıştıklarını belirtmiştir. Azimli bireyler başarıya bir maraton olarak yaklaşırlar. Azimli bireyleri diğerlerinden ayıran ve avantaj sağlayan özellikleri ise dayanıklılıktır (Bashant, 2014; Duckworth ve ark., 2007, s.1088). Onlar hedefe ulaşmada engeller ile karşılaşsalar ya da olumlu geri bildirimlerin yokluğunda bile hedeflerinden uzak durmazlar (Duckworth ve Quinn, 2009, s.166).

Kavramı benzer şekilde tanımlayan Seligman ve Peterson'a (2004) göre azim, engellere, zorluklara veya caydırıcılıklara rağmen hedefe yönelik bir eylemin gönüllü olarak sürdürülmesine olanak sağlayan bir özelliktir. 
Bir diğer araştırmacı ise azimi uygulama ile ilgili işlevlerimizi, deneyimlerimizi, odaklanma ve kontrol etme becerimizi düzenleyen ve izleyen özellik olarak tanımlar. Sahip olduğumuz azmimiz, işimiz yanlış gittiğinde nasıl cevap vereceğimizi belirlememize yardımcı olur. Çoğumuz, plan yapmamızı, çalışmamızı ve başarılı olmamızı sağlayan rutinleri azim sayesinde geliştirebiliriz. Azim bize psikolojik sağlamlık veren önemli bir faktördür. Bu sadece bizim bir göreve odaklanmamızı sağlamakla kalmaz aynı zamanda başarısız olduğumuzda sebat etmemizi de sağlar. Azimin sağladığı öz-izleme ve duygusal kontrol, uygulama ile ilgili işleyişimizin önemli bir bileşenidir (Hoerr,2012).

Bayraktutar'ın (2012) çalışmasında ise azim bir iş ya da faaliyette yönelik yapılan tercih ve bu tercihten sonra gösterilen ciddiyet ve kararlılık olarak tanımlanmaktadır. Birey daha henüz işe başlamadan önce bilişsel olarak işi tamamlama konusunda tercihte bulunursa azim, bulunmaz ve karar vermede zorluk çekerse duraksama ve şaşkınlık ortaya çıkmaktadır. Azim, hem sosyal hem de duygusal bir özellik ya da ahlaki bir değer şeklinde tanımlanmaktadır (Sarıçam vd., 2016).

Mutluluk hakkında yapılan çalışmaların tarihi milattan önceki yıllara dayanmaktadır. İlk olarak mutluluk ile ilgilenen ve çalışanlar filozoflar olmuşlardır. İnsanların ilgisini çekebilen bir konu olduğu için daha sonra psikoloji temelli tanımlar mutluluğu açıklamaya çalışmıştır. Hem felsefi hem de psikolojik açıdan bakıldığında mutluluk genel olarak iki boyuttta değerlendirlimektedir. Birici boyut ahlaki, bir diğeri ise haz odaklıdır (Eryılmaz, 2016).

Mutluluk ile ilgili bu tarihi süreç son derece anlamlı bir karar ile devam etmektedir. Birleşmiş Milletler 20 Mart 2012 yılında, dünya üzerindeki insanların mutluluk fikrini hatırlamaları, kutlamaları ve farkındalık oluşturmak için 20 Mart'1 “Dünya Mutluluk Günü” ilan etti. Birleşmiş Milletlerin Merkezinin yer aldığı Amerika başta olmak üzere birçok üye ülkede dernekler, sivil toplum kurumları, kamu eli ile eğitim, kültür ve sosyal faaliyetlerle bu gün renkli bir şekilde kutlanmaktadır (https://www.aksam.com.tr).

Mutluluk kelime anlamı olarak "bütün özlemlere eksiksiz ve sürekli olarak ulaşılmaktan duyulan kıvanç durumu, mut, ongunluk, kut, saadet, bahtiyarlık, saadetlilik" olarak tanımlanmıştır (TDK, 2011). 
Frued (2003) mutluluğu insanın sevebilmesi ve çalışabilmesi olarak tanımlamaktadır. Veenhoven mutluluğu anlamlı yaşama yeteneği ve anlamlı yaşam olarak tanımlamaktadır. Aristotales'e göre mutluluk bir araç değildir, ulaşılması gereken bir amaçtır. İnsanlar mutlu oldukları için bir iş, faaliyet ya da görevlerini yapmak yerine; tüm bunları mutlu olmak için yapmalıdır.

Mutluluk psikolojik açıdan incelendiğinde özellikle üç temel boyut dikkati çekmektedir. Haybron (2000), bu boyutları aşağıdaki gibi ele almıştır.

1. Sağduyuya Dayalı Mutluluk: Akla uygun, akliselim kararlar verme becerisi olarak kavramsallaştırılmıştır. Sağduyuya göre kararlar almak ve uygulamak bireyin iyilik halini katkı sağlayaktır.

2. Yaşam Doyumuna Dayalı Mutluluk: Psikolojik açıdan değerlendirildiğinde ikinci olarak yaşam doyumu gelmektedir. Bireyler yaşamlarından tatmin sağlayıcı davranışlar sergilediklerinde memnun olma düzeyleride artmaktadır. Memnuniyet seviyesini olumlu olarak gördüğ̈̈nde ve değerlendirdiğine birey mutlu olmaktadır.

3. Haz Temelli Mutluluk: Felsefi olarak değerlendirildiğinde haz, bir şeyden duygusal ve manevi olarak sevinç duyma olarak tanımlanır. Psikolojik bakış açısına göre ise haz, devam ettirilmesi gereken 1 lımlı ve tatmin edici coşku olarak incelenir. Haz temellli mutluluğun iki önemli boyutu vardır. Bunlardan ilki insanların rahatsız oldukları, olumsuz deneyimleden uzak durmalardır. İkinci boyut ise hoşnutluk veren, olumlu yaşantıların insanların hayatında yer almasıdır. Sonuç olarak insanlar rahatsız edici davranışlardan uzak, hoşnut oldukları davranışlara ne kadar yakınlarsa mutluluk seviyeleri artacaktır (Eryılmaz, 2016).

Azim ve mutluluk değişkenlerinin birlikte incelendiği araştırmada Yoncalık (2018), azim değişkeninin lise öğrencilerinin yaşam doyumlarını etkilediği sonucuna ulaşmıştır. Yapılan analiz sonucunda azim değişkeninin mutluluk aracı değişken olarak kullanıldığında öğrencilerin yaşam doyumları üzerindeki etkisinin \%41 olduğu, azim değişkeninin umutsuzluk ve mutluluk aracı değişken olarak kullanıldığında öğrencilerin yaşam doyumlarını üzerindeki etkisinin \%17 olduğu sonucuna ulaşmıştır. 
Sheehan (2014), araştırmasında alternatif bir liseye atanan öğrenciler ile geleneksel bir lisedeki öğrenciler arasındaki umut, azim, mutluluk, yaşam doyumu ve akademik başarıdaki farklılıkları incelemiştir. Yapılan analiz sonucunda alternatif ve geleneksel lise öğrencilerinin mutluluk ve azim düzeyleri arasında anlamlı bir farkın olmadığı sonucuna ulaşılmıştır. Ayrıca umut değişkeninin akademik başarıyı yordamada etkin olduğu tespit edilmiştir.

$\mathrm{Bu}$ araştırma ile meslek yüksekokulu öğrencilerinin azim seviyeleri ile mutluluk düzeyleri arasındaki ilişkinin incelenmesi amaçlanmaktadır. Alanyazın incelemesinde azim ve mutluluk içeren sinırlı sayıda araştırmaya ulaşılmıştır. Sonuç olarak, üniversite öğrencilerinin azim ve mutluluk düzeylerinin incelendiği sinırlı sayıda araştırma olması nedeniyle yapılan araştırma ilgili alanyazına fayda sağlayacığı düşünülmüştür.

\section{Yöntem}

\section{Araştırmanın Modeli}

Bu çalışmada nicel araştırma yöntemlerinden genel tarama modellerinden ilişkisel tarama tekniği kullanılmıştır.

\section{Çalışma Grubu}

Çalışma grubunu seçkisiz olmayan örnekleme yöntemlerinden uygun örnekleme yöntemiyle seçilen Kazım Karabekir Meslek Yüksekokulu'nda farklı bölümlerde öğrenim görmekte olan 273'ü kadın, 81'i erkek toplam 354 öğrenci oluşturmaktadır.

Sosyal bilimlerde en yaygın kullanılan örnekleme türlerinden biri uygun örneklemedir. Uygun örneklemede, araştırmacılar katılımcları ulaşması kolay, araştırma için uygun ve gönüllü bireylerden seçmektedir (Gravetter ve Forzano, 2012, akt: Başaran, 2017). Çalışma grubunun demografik bilgileri tabloda sunulmuştur. 
Tablo 1. Çalışma Grubunun Demografik Özellikleri

\begin{tabular}{llll}
\hline & & $\mathbf{n}$ & $\mathbf{\%}$ \\
\hline Cinsiyet & Kadın & 273 & 77.1 \\
\hline & Erkek & 81 & 22.9 \\
\hline Eğitim Düzeyi & Toplam & 354 & 100 \\
\hline
\end{tabular}

Tablo 1' e göre çalışma grubunun 273' ü $(\% 77,1)$ kadın, 81'i $(\% 22,9)$ erkek öğrencilerden oluşmaktadır. Katılımcıların tamamı ön lisans eğitimine devam etmektedirler ve yaş ortalamaları 20.10' dur.

\section{Veri Toplama Araçları}

Kısa Azim Ölçeği: Kısa Azim Ölçeği Duckworth ve Quinn (2009) tarafından geliştirilen ölçeğin orijinal dili İngilizcedir. Türkçe uyarlaması Sarıçam, Çelik ve Oğuz (2016) tarafından yapılan kendini değerlendirmeye yönelik 5'li likert tipi bir ölçme aracıdır. Ölçek, 8 maddeden oluşan 2 alt boyutlu (İlginin tutarlılığı, gayrette 1srar) bir yapıya sahiptir. İlginin tutarlılığı alt boyutunda yer alan 1.3.5. ve 6. Maddeler ters kodlanmaktadır.

Doğrulayıc faktör analizi sonucu 2 boyutlu modelin uyum indeksi değerleri $(\chi 2(19, \mathrm{~N}=1,554)=188.52, \mathrm{p}<.001$; RMSEA $=.076(90 \% \mathrm{CI}=.066-$ .086), CFI = .96) olarak bulunmuştur. Ölçeğin faktör yükleri. 37 ile .80 arasında sıralanmaktadır. Benzer ölçek geçerliliği çalışmasında kısa azim ölçeği ile uzun azim ölçeği arasında $r=.91, \mathrm{p}<.01$ önem düzeyinde ilişki bulunmuştur. Cronbach alfa iç tutarlık güvenirlik katsayıları gayrette ısrar alt boyutu için. 70, ilginin tutarlılı̆̆1 alt boyutu için .77 ve ölçeğin bütünü için .82 olarak bulunmuştur.

Oxford Mutluluk Ölçeği Kısa Formu: Oxford Mutluluk Ölçeği Kısa Formu (Hills ve Argyle, 2002) mutluluk düzeyini değerlendirebilmek amaciyla geliştirilmiş 8 maddelik ve tek boyutlu bir ölçektir. Doğan ve Çötok (2011) tarafından Türkçe'ye uyarlanmıştır. Faktör analizi sonuçları ölçeğin tek faktörlü bir yapıya sahip olduğunu ortaya koymuştur. Benzer ölçek geçerliği kapsamında Oxford Mutluluk Ölçeği Kısa Formu ile Yaşam Doyumu Ölçeği ve Yaşam Yönelimi Testi arasında pozitif yönde anlamlı ilişkiler bulunmuştur. Oxford Mutluluk Ölçeği Kısa Formu ile Zung Depresyon Ölçeği arasında ise 
negatif yönde anlamlı ilişki bulunmuştur.Ölçeğin iç tutarlık ve test tekrar test güvenirlik katsayıları sırasıyla. 74 ve .85 olarak saptanmıştır.

Tablo 2. Ölçme Araçlarının Puan Değerleri

\begin{tabular}{lllll}
\hline Ölçek & \multicolumn{1}{c}{$\mathbf{n}$} & $\overline{\mathrm{X}}$ & ss. & $\begin{array}{l}\text { Cronbach } \\
\text { Alpha }\end{array}$ \\
\hline $\begin{array}{l}\text { Oxford Mutluluk } \\
\text { Ölçeği Kisa Formu }\end{array}$ & $\begin{array}{l}7 \text { (1.ve7. maddeler ters } \\
\text { kodlanmaktadır.) }\end{array}$ & 23.33 & 4.84 & .70 \\
\hline $\begin{array}{l}\text { Kisa Azim Ölçeği } \\
\text { (İlgi Alt Boyutu) }\end{array}$ & $\begin{array}{l}4 \text { (1.3.5. ve 6. maddeler } \\
\text { ters kodlanmaktadır) }\end{array}$ & 12.06 & 3.47 & .55 \\
\hline $\begin{array}{l}\text { Kisa Azim Ölçeği } \\
\text { (Sebat Alt Boyutu) }\end{array}$ & 4 (2.4.7. ve 8. maddeler) & 15.27 & 3.07 & .65 \\
\hline
\end{tabular}

Ölçeklere ilişkin bilgiler Tablo 2' de sunulmuştur. Tablo 2' de toplanan verilerden elde edilen sonuçlara bakıldığında, Oxford Mutluluk Ölçeği Kısa Formu ölçeği için güvenirlik katsayıları (cronbach alpha) oldukça güvenilir kabul edilen değere sahip olduğu, Kısa Azim Ölçeği için ise güvenirlik katsayıları (cronbach alpha) güvenilir ve/veya oldukça güvenilir değerlere sahip olduğu bulunmuştur.

\section{Verilerin Analizi}

Elde edilen verilerin istatistiki analizi SPSS 21.00 yardımıla yapılmıştır. Araştırmaya katılanların demografik bilgilerinin dağılımlarının belirlenmesi için tanımlayıcı istatistik yöntemleri olan yüzde (\%) ve frekans (f) yöntemleri kullanılmıştır. Verilerin normal bir dağılıma sahip olduğu tespit edildikten sonra anlamlı farklılıkların analizi için iki faktörlü değişkenler için $t$ testi yapılmıştır. Anlamlılık düzeyi ise $\mathrm{p}<0,05$ olarak kabul edilmiştir. Ayrıca azim ile mutluluk ölçeği puanları arasındaki ilişkilerin tespitinde Pearson Momentler Çarpım Korelasyon analizi kullanılmıştır.

\section{Bulgular}

Tablo 3' e göre katılımcıların azim ile mutluluk ölçekleri puanları cinsiyet değişkenine göre anlamlı bir farklılık gösterip göstermediğini belirlemek amaciyla yapılan t-testi sonucunda grup ortalamaları arasında anlamlı fark bulunmamıştır. 
Tablo 3. Cinsiyet Değişkenine Göre Azim ve Mutluluk Ölçeklerinin t Testi Sonucu

\begin{tabular}{lllllll}
\hline & Cinsiyet & $\mathbf{n}$ & $\overline{\mathbf{X}}$ & ss. & $\mathbf{t}$ & $\mathbf{p}$ \\
\hline \multirow{2}{*}{ Kısa Azim Ölçeği } & Kadın & 273 & 27.28 & 4.70 & & \\
\cline { 2 - 5 } & Erkek & 81 & 27.52 & 4.26 & -.413 & \multirow{2}{*}{.352} \\
\hline Oxford Mutluluk Ölçeği Kısa Formu & Kadın & 273 & 23.51 & 4.84 & & \\
\cline { 2 - 5 } & Erkek & 81 & 22.72 & 4.83 & 1.30 & \multirow{2}{*}{.832} \\
\hline
\end{tabular}

$p<.05$

Tablo 4. Azim ve Mutluluk Ölçekleri Arasında Pearson Momentler Çarpım Korelasyon Analizi Sonucu

\begin{tabular}{lccc}
\hline & $\mathbf{n}$ & $\mathbf{r}$ & $\mathbf{p}$ \\
\hline $\begin{array}{l}\text { Kısa Azim Ölçeği } \\
\text { Oxford Mutluluk Ölçeği Kısa Formu }\end{array}$ & 354 & .350 & .000 \\
\hline
\end{tabular}

$$
p<.05
$$

Tablo 4'e göre, katılımcıların, azim puanları ile mutluluk puanları arasında bir ilişkinin olup olmadığını belirlemek amacıyla yapılan Pearson Çarpım Moment Korelasyon analizi, azim ve mutluluk puanları arasında, pozitif yönde ve zayıf düzeyde anlamlı bir ilişki olduğu bulunmuştur. $(\mathrm{r}=.350 ; \mathrm{p}<.05)$

\section{Tartışma}

Bu araştırma meslek yüksekokulu öğrencilerinin azim ve mutluluk düzeyleri arasındaki ilişkiyi belirlemek ve azim ve mutluluk düzeyleri cinsiyet değişkenine göre anlamlı bir farklılaşma olup olmadığını ortaya koymak amacıyla yapılmıştır. Araştırmanın temel varsayımı meslek yüksekokulu öğrencilerinin azim düzeyleri yüksek olanların mutluluk düzeylerinin de buna bağlı olarak yüksek olacağı yönündedir. Araştırma sonuçları bu temel varsayımı doğrular niteliktedir.

Bulgulardan elde edilen sonuçlara göre; azim ve mutluluk düzeyleri arasında pozitif yönde ve anlamlı bir ilişki olduğu saptanmıştır. Azim ve mutluluk kavramlarını inceleyen araştırmalar değerlendirildiğinde benzer sonuçlar bulunmaktadır. İlkokul ve ortaokul öğrencileri ile yapılan bir çalışmada, öğrencilerin akademik azim seviyeleri yükseldikçe, okul ortamında yükselen bir düzeyde pozitif yaşantılara ve iyi oluşa sahip olma düzeyleri olabileceğini göstermektedir. Akademik azim ölçeği puanı ile pozitif yaşantılar ölçeğinin 
minnettarlık, yaşam coşkusu, iyimserlik ve sebat alt boyutları arasındaki ilişkinin pozitif ve orta düzeyde anlamlı olduğu görülmüştür. (Bozgün ve Başgün, 2018).

Araştırma sonuçlarına benzer bir diğer çalışmada ise, araştırmaya katılan lise öğrencilerinin azim, umutsuzluk ve mutluluğun, yaşam doyumları ve akademik başarıların belli oranlarda yordadığı bulunmuştur (Yoncalık, 2018). Yaşam doyumu Haybron'nun (2000) mutluluk sinıflamasında yer aldığı için azim ve mutluluk arasındaki anlamlı ilişkinin olduğu şeklinde değerlendirilebilir.

Bir başka çalışmada ise öğrencilerin mutluluk ve umutsuzluk düzeyleri arasında negatif yönde istatistiksel olarak anlamlı bir ilişki bulunmuştur. Aynı araştırmanın bir diğer sonucu ise, öğrencilerin geleceğe yönelik plan yapıp yapmadıklarına ve geleceğe ilişkin bakış açılarına göre mutluluk düzeyleri arasında istatistiksel açıdan anlamlı bir fark bulunmuştur (Namdar,2018). Azmi oluşturan dört önemli özellik ilgi, uygulama, amaç ve umuttur (Duckworth, 2018). Bu sonuç ile mutluluk ve azimin iki önemli özelliği olan amaç ve umut arasında anlamlı bir ilişki olduğu söylenebilir.

Bir diğer bulgu ise meslek yüksekokulu öğrencilerinin azim düzeyleri cinsiyet değişkenine göre istatistiksel açıdan anlamlı derecede farklılık göstermemektedir. Bu bulgu azim çalışmalarında cinsiyet değişkenine göre farkl1lık olmadığı yönünde sonuç bulan çalışmalar ile benzerlik taşımaktadır. Yurtdışı literatürde yapılan çalışmalar (Gamel,2014, Wallace, 2015, Kwon, 2018,) incelendiğinde, cinsiyet değişkenine göre katılımcıların azim düzeyleri arasında istatistiksel açıdan anlamlı derecede farklılaşma bulunamamıştır. Benzer olmayan sonuç bulan bir araştırmada ise azim düzeyleri ile cinsiyet arasında anlamlı bir fark bulunmuştur. Kadınlara ait azim puanı erkek katılımcılara göre daha yüksek olarak belirlenmiştir (Farroll, 2016). Yurtiçi literatürde yapılan azim çalışmalarında cinsiyet değişkenin incelendiği tek araştırmada ise katılımcıların cinsiyet ve yaş değişkenlerine göre sebatlı olma düzeyleri arasında istatistiksel olarak anlamlı bir fark bulunamamıştır (Ömürlü, 2018).

Meslek yüksekokulu öğrencilerinin mutluluk düzeyleri cinsiyet değişkenine göre istatistiksel açıdan anlamlı derecede farklılık göstermemektedir. Bu bulgu mutluluk çalışmalarında cinsiyet değişkenine göre farklılık olup olmadığını analiz eden çalışmalar ile benzerlik taşımaktadır. Mutluluk değişkenin cinsiyet değişkenine göre anlamlı derecede 
farklılaşmadığı sonucu, muttluluk ile ilgili yapılan çalışmlar ile benzerlik göstermektedir. Kızılay (2018) ve Namdar'ın (2018) araştırmalarında katılımcların mutluluk düzeylerinin cinsiyet değişkenine göre anlamlı bir farklılık gösterip göstermediğini belirlemek için yaptıkları ilişkisiz grup t testi sonucunda grup ortalamaları arasındaki fark istatistiksel açıdan anlamlı olarak bulunmamıştır.

\section{Sonuç ve Öneriler}

Meslek yüksekokulu öğrencilerinin azim ve mutluluk düzeyleri arasında anlamlı bir ilişki olduğu soncuna ulaşılmıştır. Bununla birlikte meslek yüksekokulu öğrencilerinin azim ve mutluluk düzeyleri cinsiyet değişkenine göre farklılaşmadığı tespit edilmiştir.

Özet olarak, bireylerin sahip oldukları azim seviyeleri onların yaşam doyumlarını olumlu biçimde etkilemektedir (Yoncalık, 2018). Yaşam doyumu artan bireylerin buna bağlı olarak mutluluk seviyeleride yükselmektedir (Eryılmaz, 2016). Yaşamlarında mutlu ve azimli olan bireyler toplumun refah seviyesine katkıda bulunabilir.

Araştırmanın sonuçlarına göre aşağıda yer alan önerilerde bulunulabilir:

Azim ve mutluluk düzeyleri ile ilgili farklı boyutlarda diğer öğrenim kademelerinde, örneklem gruplarında araştırmalar yapılması ilgili kavramların öneminin anlaşılmasına fayda sağlayabilir. Türk kültüründe azim tanımlamasına katkı sağlayacak nitel çalışmalar yapılabilir. Azimi oluşturan boyutların ortaya çıkarılması için hem nitel hem de nitel araştırmalar alanyazına fayda sağlayabilir. Özellikle azim kavramı ile ilgili olarak psiko-eğitim çalışmalarına ihtiyaç vardır. Öğrencilerin azim seviyelerini artırmaya yönelik psiko-eğitim uygulamaları eğitim faaliyetleri açısından önemli olabilir. 


\title{
EXTENDED ABSTRACT
}

\section{Investigation Of The Level Of Grit And Happiness Of Vocational High School Students}

\author{
Nezir Ekinci - Erdal Hamarta \\ Karamanoğlu Mehmetbey University, Necmettin Erbakan University
}

People need to stay away from negative thoughts and emotions throughout their lives and be happy to develop themselves (Eryılmaz, 2016). The selfimprovement of the happy individuals can be realized as a result of the transformation of the existing talent into performance, labor and effort in line with its goals. It is a repetitive effort that is necessary for the individual to transform his / her abilities into a skill. Continuous efforts will turn the skill into success. For long-term gifts, people need to be determined and endeavored to overcome obstacles and achieve their goals (Duckworth, 2007).

University students are at a critical stage for career choice and success, which is one of the important periods in their lives. In order for this phase to be successful, a cognitive boundary goal, behavioral repetitive practice, and emotional interest and hope are required to be present in students (Duckworth, 2018). The personality traits indicated are not owned or possessed. Students will be able to attain goals that are appropriate to their own abilities and values, realize and develop their interests and deepen their learning. It can make discipline a habit; they can strive regularly and continuously for their daily purposes (Duckworth, 2007). I mean students doing all these things; You may face various obstacles while working for your long-term goals. In these cases, those who have the personality of hope personality will continue their struggle. Four valuable personality traits also constitute the level of grit of the individual (Duckworth, 2007, 2018).

The main aim of this study is to investigate the levels of happiness and grit of vocational school students and the sub-purpose of this study is to investigate whether there is a difference in grit and happiness levels according to gender variable. The assumption that students who continue their lives with determination will get more satisfaction from life forms the basis of this research. It is expected that happiness levels of students who get more satisfaction from their lives will increase (Eryılmaz, 2016). 


\section{Method}

\section{The Research Model}

In this study, relational scanning technique, one of the quantitative research methods, was used.

\section{Study group}

The study group consisted of 354 students, 273 females and 81 males, studying at different departments of Kazım Karabekir Vocational School of Higher Education.

One of the most commonly used sampling types in social sciences is appropriate sampling. In appropriate sampling, researchers select participants from individuals that are easy to reach, suitable for research, and volunteer (Gravetter and Forzano, 2012, cited in Başaran, 2017). (Basaran, Y. K. (2017). Sampling theory in social sciences. The Journal of Academic Social Sciences. 47. 480-495. 10.16992 / ASOS.12368.)

Short Grit Scale: Short Grit Scale The original language of the scale developed by Duckworth and Quinn (2009) is English. It is a 5-point Likerttype measurement tool for Turkish self-assessment by Sarıçam, Çelik and Oğuz (2016). The scale has 2 sub-dimensions (consistency of interest, persistence in effort) consisting of 8 items. The consistency of interest is in 1.3.5. and 6 are reverse coded.

Confirmatory factor analysis showed that the fit index values of the 2D model $(22(19, \mathrm{~N}=1.554)=188.52, \mathrm{p}<.001 ;$ RMSEA $=.076(90 \% \mathrm{CI}=.066-$ $.86), \mathrm{CFI}=.96)$. Factor loads of the scale. They range from 37 to .80 . In the similar scale validity study, a significant correlation was found between short tenacity scale and long tenacity scale at $\mathrm{r}=.91, \mathrm{p}<.01$. Cronbach's alpha internal consistency reliability coefficients for gay-rette insistence on the subdimension. $70, .77$ for the consistency subscale of interest and .82 for the whole scale.

Oxford Happiness Scale Short Form: The Oxford Happiness Scale Short Form (Hills and Argyle, 2002) is an 8-item, one-dimensional scale developed to assess the level of happiness. It was adapted into Turkish by Doğan and Çötok (2011). The results of the factor analysis revealed that the scale 
had a single factor structure. Within the scope of similar scale validity, a significant positive relationship was found between the Oxford Happiness Scale Short Form and the Satisfaction with Life Scale and Life-Oriented Test. A significant negative correlation was found between the Oxford Happiness Scale Short Form and Zung Depression Scale. Internal reliability and test-retest reliability coefficients of the scale were respectively. 74 and .85 .

\section{Results and Discussion}

In order to determine whether the participants' grit and happiness scales showed a significant difference according to gender variable, there was no significant difference between t-test results.Pearson Product Moment Correlation Analysis, which was conducted to determine whether there was a relationship between the participants' grit scores and happiness scores, was found to be positively and weakly correlated between grit and happiness scores. $(\mathrm{r}=.350 ; \mathrm{p}<.05)$

This research was conducted to determine the relationship between grit and happiness levels of vocational school students and to determine whether there is a significant difference between grit and happiness levels according to gender variable. The main assumption of the study is that the happiness levels of the students who have high levels of grit will be high. The results of the research confirm this basic assumption.

According to the results obtained from the findings; There was a positive and significant relationship between grit and happiness levels. There are similar results when the studies investigating the concepts of grit and happiness are evaluated. In a study conducted with primary and secondary school students, it shows that as students' levels of academic grit increase, they may have positive experiences and well-being levels in the school environment. The relationship between academic grit score and positive experiences scale was found to be positive and moderate in relation to gratitude, life enthusiasm, optimism and persistence sub-dimensions. (Bozgun and Basgun, 2018).

In another study similar to the results of the study, it was found that grit, despair and happiness of the high school students who participated in the research predicted their life satisfaction and academic success (Yoncalık, 2018). Since life satisfaction is included in the happiness classification of 
Haybron (2000), it can be considered that there is a significant relationship between determination and happiness.

In another study, a statistically significant negative correlation was found between students' happiness and hopelessness levels. As a result of the same research, a statistically significant difference was found between students' happiness levels according to whether they made plans for the future and their perspectives regarding the future (Namdar, 2018). The four important specialties that create grit are interest, practice, purpose and hope (Duckworth, 2018). It can be said that there is a meaningful relationship between this result and happiness and determination, which are two important characteristics of purpose and hope.

Another finding is that the grit levels of vocational school students do not show statistically significant difference according to gender variable. This finding is similar to the studies that found no difference in grit studies according to gender. When the studies in the foreign literature (Gamel, 2014, Wallace, 2015, Kwon, 2018,) were examined, no statistically significant difference was found between the grit levels of the participants according to the gender variable.

Happiness levels of vocational school students do not show statistically significant difference according to gender variable. This finding is similar to the studies that analyze whether happiness studies differ according to gender variable. Happiness variable does not differ significantly according to gender variable, it is similar to the studies on happiness. In Kizilay (2018) and Namdar's (2018) research, the difference between the group averages was not statistically significant as a result of the unrelated group $t$ test performed to determine whether the happiness levels of the participants showed a significant difference according to gender variable.

It was concluded that there is a significant relationship between grit and happiness levels of vocational school students. However, it was found that the grit and happiness levels of the students of the vocational college did not differ according to the gender variable. In summary, grit levels of individuals positively affect their life satisfaction (Yoncalık, 2018). Happiness levels of individuals with increased life satisfaction increase as well (Eryılmaz, 2016). Individuals who are happy and determined in their lives can contribute to the welfare of society. 
According to the results of the research, the following suggestions can be made:

Conducting researches in different levels of grit and happiness in other learning levels and sample groups may help to understand the importance of related concepts. Qualitative studies that can contribute to the definition of grit in Turkish culture can be done. Both qualitative and qualitative research can help the literature to reveal the dimensions that constitute grit. There is a need for psycho-educational studies, especially in relation to the concept of grit. Psycho-educational practices aimed at increasing students' grit levels may be important for educational activities.

\section{Kaynakça / References}

Abuhassàn, A. ve Bates, T. C. (2015). Distinguishing effortful persistence from conscientiousness. Journal of Individual Differences, 36(4), 205-214.

Bashant, J. (2014). Developing grit in our students: Why grit is such a desirable trait, and practical strategies for teachers and schools. Journal for Leadership and Instruction, 13(2), 14-17.

Başaran, Y. K. (2017). Sosyal bilimlerde örnekleme kuramı. The Journal of Academic Social Sciences. 47. 480-495. 10.16992/ASOS.12368.

Bozgün, K. ve Başgül, M. (2018). Akademik Azim Ölçeğinin Türkçeye uyarlanması: Geçerlik ve güvenirlik çalışması. Akademik Sosyal Araştırmalar Dergisi, 6(85), 435-445. doi:http://dx.doi.org/10.16992/ASOS.14521

Collaco, C. M. (2018). What do we really know about Grit? A multivariate statistical investigation on the construct validity of Grit. Unpublished doctoral dissertation, The University of San Francisco, San Francisco.

Doğan, T., ve Akıncı Çötok, N. (2016). Oxford mutluluk ölçeği kısa formunun Türkçe uyarlaması: Geçerlik ve güvenirlik çalışması. Türk Psikolojik Danışma ve Rehberlik Dergisi, 4(36), 165- 172. http://pdrdergisi.org/index.php/pdr/article/view/100/101 adresinden erişildi.

Duckworth, A. L. (2006). Intelligence is not enough: Non -IQ predictors of achievement. Dissertations available from ProQuest. No:AAI3211063. https://repository.upenn.edu/dissertations/AAI3211063

Duckworth, A. L., Peterson, C., Matthews, M. D. ve Kelly, D. R. (2007). Grit: Perseverance and passion for long-term goals. Journal of Personality and Social Psychology, 92(6), 1087-1101. doi:10.1037/00223514.92.6.1087 
Duckworth, A. L., ve Quinn, P. D. (2009). Development and validation of the short grit scale (Grit-S). Journal of Personality Assessment, 91(2), 166174. doi:10.1080/00223890802634290

Duckworth, A. (2018). Azim sabır, tutku ve kararlilı̆ıı gücü. İstanbul: Pegasus Yayınevi.

Dumfart, B. ve Neubauer, A. C. (2016). Conscientiousness is the most powerful noncognitive predictor of school achievement in adolescents. Journal of Individual Differences, 37(1), 8-15. doi:10.1027/1614-0001/a000182

Eryılmaz, A. (2016). Herkes için mutluluğun başucu kitabı teoriden uygulamaya pozitif psikoloji. Ankara: Pegem Akademi.

Farroll, J. C. (2016). Grit, deliberate practice, and athletic training education: Factors that determine board of certification exam success (Order No. 10307061). Available from ProQuest Dissertations \& Theses Global. (1873447170). https://search.proquest.com/docview/1873447170?accountid=25089 adresinden erişilmiştir.

Gamel, M. (2014). Impact of character development and empowerment program on Grit and resilience growth in early and middle adolescents. Unpublished doctoral dissertation, Kennesaw State University, Georgia.

Hoerr, T.R. (2012). Fostering grit: How do I prepare my students for the real world? Alexandria. VA: ASCD.

Dünya Mutluluk Günü ne zaman? İşte 20 Mart Dünya Mutluluk Günü mesajları ve sözleri. (Mart 20, 2019). Akşam, 21.05.2019 tarihinde https://www.aksam.com.tr/magazin/dunya-mutluluk-gunu-ne-zaman-iste-20-mart-dunya-mutluluk-gunu-mesajlari-ve-sozleri/haber832834 adresinden erişilmiştir.

Türk Dil Kurumu Sözlük, TDK. (2011). Büyük Türkçe sözlük. Ankara: TDK Yayınları.

Kelly, D. R., Matthews, M. D., ve Bartone, P. T. (2014). Grit and hardiness as predictors of performance among West Point cadets. Military Psychology (American Psychological Association), 26(4), 327-342. doi:10.1037/mil0000050

Kızılay. A. (2018). Psikolojik Güçlendirmenin mutluluk ve iş tatmini üzerindeki etkisi. Yayınlanmamış Yüksek Lisans Tezi. Sosyal Bilimler Enstitüsü, Üsküdar Üniversitesi, İstanbul. 
Kwon, H. W. (2018). The sociology of grit: Cross-cultural approaches to social stratification (Order No. 10811496). Available from ProQuest Dissertations \& Theses Global. (2115839979). Retrieved from https://search.proquest.com/docview/2115839979?accountid=25089

Namdar, A. (2018). Bir grup öğrencide umut, kaygı ve mutluluk arasındaki ilişki. Yayınlanmamış Yüksek Lisans Tezi. Sosyal Bilimler Enstitüsü, Üsküdar Üniversitesi, İstanbul.

Ömürlü, L.S. (2018). Üstbiliş ve ahlaki üstbiliş ile sebatli olma arasindaki ilişkinin eeg tekniğiyle gözlemlenmesi. Yayınlanmamış Yüksek Lisans Tezi. Sağlık Bilimleri Enstitüsü, Üsküdar Üniversitesi, İstanbul.

Perkins-Gough, D. (2013). The significance of grit: A conversation with Angela Lee Duckworth. Educational Leadership, 71(1), 14-20.

Peterson, C., ve Seligman, M. E. P. (2004). Character strengths and virtues: A handbook and classification. Washington, DC: American Psychological Association, and New York, NY: Oxford University Press.

Sarıçam, H., Çelik, İ., ve Oğuz, A. (2016). Turkish adaptation of the Short Grit Scale (Grit-S): Validity and reliability study. Uluslararası Türkçe Edebiyat Kültür Eğitim Dergisi, 5(2), 927-935. Doi Number: http://dx.doi.org/10.7884/teke.622

Sheehan, K. (2014). Storm clouds in the mind: A comparison of hope, grit, happiness and life satisfaction in traditional and alternative school students (Order No. 3609624). Available from ProQuest Dissertations \& Theses Global. (1498550277). Retrieved from https://search.proquest.com/docview/1498550277?accountid=25089

Soutter, M., ve Seider, S. (2013). College access, student success, and the new character education. Journal of College and Character, 14(4), 351-356. doi:10.1515/jcc- 2013-0044

Wallace, R. L. (2015). Grit and student performance: A mixed-method analysis of a nontraditional technical high school and a traditional high School. Unpublished doctoral dissertation, Lindenwood University, Kingshighway, ABD.

Yoncalık, O., 2018. Lise öğrencilerinde azim, mutluluk ve umutsuzluğun yaşam doyumları ve akademik başarılarına etkisi. Yayınlanmamış Yüksek Lisans Tezi. Gazi Üniversitesi, Eğitim Bilimleri Enstitüsü, Ankara. 


\section{Kaynakça Bilgisi / Citation Information}

Ekinci, N. ve Hamarta, E. (2020). Meslek yüksekokulu öğrencilerinin azim ile mutluluk düzeylerinin incelenmesi. OPUS-Uluslararası Toplum Araştırmaları Dergisi, 15(21), 125-144. DOI: 10.26466/opus.569805 